\title{
SATISFACTION ON DELIVERY CARE SERVICES AMONG RURAL WOMEN IN SARAWAK, MALAYSIA: A CROSS-SECTIONAL COMMUNITY-BASED STUDY
}

\author{
Deburra Peak Ngadan', Md Mizanur Rahman¹, Mohammad Taha Arif ${ }^{1}$ \\ ${ }^{1}$ Department of Community Medicine and Public Health, \\ Faculty of Medicine and Health Sciences, \\ Universiti Malaysia Sarawak, Malaysia 94300, Samarahan, Sarawak, Malaysia \\ Email: rmmizanur@unimas.my
}

\begin{abstract}
The improvement of quality in maternity care services is an effective strategy to reduce maternal mortality. The utilisation of the maternity services and its satisfaction indirectly measure the quality of services. This study aimed to assess the level of satisfaction with delivery care and also to identify the factors influencing the satisfaction among women on the quality of delivery care services in Sarawak. A cross-sectional study was conducted in the three main zones of Sarawak, Malaysia. A total of 1236 completed data were analysed. Data was collected using the validated Patient Satisfaction Questionnaire (PSQ-18, Short Form) by face to face interview. Data entry and analysis was done by SPSS version 22.0 software. A p-value of less than 0.05 was considered statistically significant. A multinomial logistic regression analysis revealed that Bidayuh ethnics were $28.6 \%$ less likely to have good satisfaction with delivery care than the other ethnic groups. The respondents were 1.806 times more likely to have the average satisfaction and 1.972 times more likely to have good satisfaction on delivery care if a doctor attended the latter. Similarly, the respondents were 2.29 times highly satisfied if the out of pocket expenses were less than MYR 91.50 (US \$21.73) compared to 2.10 times in average satisfaction. Overall, the women were satisfied with the delivery care services. However, assessment of satisfaction with the services provided from the different level of health care professionals needs to be explored to gain a deeper understanding of maternal care.
\end{abstract}

Keywords: Delivery Care, Level of satisfaction, Maternal Health Services, Sarawak.

\section{INTRODUCTION}

The estimated annual rate of the global Maternal Mortality Rate has declined across the years. However, it was not enough to reach the SDG 3 target. Regionally, the southern Asian countries showed marked reduction towards achieving the SDG 3 target (World Health Organization, UNICEF, UNFPA and The World Bank, 2012; Yadav, 2012). The safe delivery program effort for pregnant mothers in Malaysia has been implemented through various Public Health activities under the Ministry of Health. These efforts include Maternal and Child Health $(\mathrm{MCH})$ Program, High-Risk Approach, Safe Motherhood and Confidential Enquiry into Maternal Deaths (Yadav, 2012). These efforts were done to improve the quality of care for pregnant mothers during their delivery to reduce the maternal mortality rate. Improvement in quality of care has been shown to reduce maternal mortality rate tremendously (World Health Organization, UNICEF, UNFPA and The World Bank, 2012; Yadav, 2012). Malaysia has reduced the Maternal Mortality Rate (MMR) from 150 per 100,000 live births (the 1950s) to 28 per 100,000 live births in 2010 parallel with the increased rate of deliveries attended by skilled professionals (Kaur, 2011; Yadav, 2012).

The utilisation of maternal health care has been encouraging over the years and up to the current date. The delivery care services in Sarawak target to have 100 per cent safe deliveries throughout the state, attended by skilled professional personnel (Bélanger-Lévesque, Pasquier, RoyMatton, Blouin, \& Pasquier, 2014) parallel to the Safe Motherhood program. Skilled personnel include all community nurses working in district $\mathrm{MCH}$ clinics and all staff nurses (with midwifery background) working in the maternity ward and labour room of a hospital setting. The public health 
policy regarding maternal health care, including delivery care, can be reflected in patients' satisfaction. Women's satisfaction with maternity services is an indirect reflection of quality service provided, resulting in increased utilisation (Dzomeku, 2011; Kyei, Campbell, \& Gabrysch, 2012). High satisfaction with delivery care would encourage use for safe delivery either in the hospital or the MHC clinics.

Satisfaction with delivery or childbirth services among mothers is divided into health care provider aspects and patients' aspects. The health care providers aspects which are associated with maternal satisfaction during delivery includes the attitude of caregivers (Dzomeku, 2011), fewer number of different caregivers during follow up (Sandall, Soltani, Gates, Shennan, \& Devane, 2016), adequacy of delivery facilities (Amentie, Muluemebetabera, \& abdulahi, 2016; Kebede, Hassen, \& Nigussie Teklehaymanot, 2016; Lumadi \& Buch, 2011), health education regarding postpartum (Lumadi \& Buch, 2011), maintenance of privacy during physical examination (Amentie et al., 2016; Lumadi \& Buch, 2011) and interpersonal skills (Amentie et al., 2016). On the other hand, patient aspects include maternal age, such as middle age (20-34 years) (Kebede et al., 2016; Yohannes, Tarekegn, \& Paulos, 2013), the level of education (Sandall et al., 2016; Yohannes et al., 2013), previous antenatal care follow up (Yohannes et al., 2013), support from partner (Kennare, Keirse, Tucker, \& Chan, 2010), expenses incurred during the delivery period of admission to hospital (Dhar et al., 2009; Kebede et al., 2016; Varma, Khan, \& Hazra, 2010) and whether the pregnancy timing (Kennare et al., 2010) was planned.

Previous studies have concentrated more on the aspect of the utilization of maternal care itself (Amano, Gebeyehu, \& Birhanu, 2012; Darega, Dida, Tafese, \& Ololo, 2016; Das et al., 2016). The perspective of customer or client satisfaction on maternal health care services is equally essential requirements of the utilisation of health care facilities. A minimal study has been done to assess client satisfaction with delivery care. In this study, the current knowledge of delivery care services was identified in the domains viz. technical aspect, financial aspect, supportive services, clinic staff, accessibility, interpersonal communication and duration spent with a doctor or skilled medical team of delivery care service provision. Study on factors associated with the level of satisfaction among the women would increase the compliance and usage of maternity services for safe delivery. Thus, in this context, the main objective of this study was to assess the level of satisfaction with delivery care and the factors associated with it.

\section{METHODS}

\section{Study Design and Sampling Procedure}

A multi-stage cluster random sampling was followed to select the respondents. This cross-sectional study was conducted in three (3) different divisions out of the eleven divisions in Sarawak. In every selected division, all districts were included and every three (3) out of five (5) villages were selected through the Mother and Child Health Clinic (MCH) registry found in their respective district $\mathrm{MCH}$ clinics. A total of 1400 household with eligible mothers were selected in the sampling frame with the help from $\mathrm{MCH}$ clinic Registry, taking all eligible mothers in the randomly selected villages. The inclusion criteria included all women who delivered in both government and nongovernmental hospitals as well as $\mathrm{MCH}$ clinic in Sarawak during their last childbirth. The mothers having the youngest child of three years and below were visited and interviewed by the researcher. Exclusion of the respondents were all women who did not consent or unwilling to participate; aged below 18 years; non-Malaysian citizenship and incapable of answering the questionnaires. 


\section{Instrument Development and Data Collection Procedure}

A modified data collection instrument was developed based on the Demographic Health Survey (DHS) Maternity component and the validated Patient Satisfaction Questionnaire (PSQ18, Short Form) (Pitaloka \& Rizal, 2006). Other relevant additional instruments were also considered (Rahman, 1997; Sarawak State Health Department, 2003). Data was collected by face to face interview using an interviewer-administered questionnaire. The questionnaire consisted of four main parts, which were 1) socio-demographic characteristics where the variables were maternal age, ethnicity, level of education, occupation, household income and family size. 2) Antenatal care history, 3) delivery care history, which includes birth attendant, mode of delivery, post-delivery attendant and out-of-pocket expenses 4) postnatal care history. For each maternity care services, patient satisfaction questions were asked regarding the services received.

Seven domains of satisfaction determined the level of satisfaction with delivery care. The domains were technical quality of the service providers (4 items), financial aspect in terms of affordability of users' fees and other services charges (3 items), supportive services from health care facilities in terms of hospital beds, food (6 items), clinic staff including behavioural issues, attention etc. (5 items), accessibility of care, mostly incorporating the physical accessibility, referral services (4 items), interpersonal communication (2 items) and duration spent with doctor or skilled health staff (2 items).

After summation of all domains score, it was checked for normality. A total score using the mean of all domains was calculated for the overall satisfaction score which gives a total mean of the seven domains. The satisfaction score was further divided into quartiles. The lowest quartile as poor and middle two quartiles as average and the last quartile categorised as highly satisfied with delivery care. Before field operation, a pre-test of the questionnaire was done in a non-sample area with the translated National language (Bahasa Malaysia) questionnaire. A minor change was made following the pre-test of the questionnaire.

\section{Data Processing and Analysis}

The collected data were checked manually for completeness and inconsistencies. A total of 1400 household were selected. However, finally, 1236 women were interviewed with a response rate of $88.3 \%$. Data entry and analysis was done using SPSS Software 22.0 version (IBM SPSS, 2013). Missing data were carefully examined and was imputed using the standard technique (Garson, 2015). After validation, descriptive analysis was done and was presented in frequency tables. A multinomial logistic regression analysis was done to identify the potential factors associated with the level of satisfaction on delivery care (Pallant, 2016; Tabachnick \& Fidell, 2013). A p-value of less than 0.05 was considered statistically significant.

\section{Ethical Considerations}

Ethical approval was obtained from the Faculty of Medicine and Health Sciences (FMHS), Universiti Malaysia Sarawak [Ref. No. UNIMAS/TNC(AA)03.02/06-11 Jld.2(87)]. Informed written consent was obtained from the respondents before data collection. The respondents were assured of data confidentiality.

\section{RESULTS}

\section{Socio-demographic Characteristics of the Respondents}

The mean (SD) age was 28.3 (6.1) years, ranging from 18 to 49 years. The highest percentage of respondents were Iban (40\%) followed by Bidayuh (30.3\%) and Malay (17.7\%). More than two-thirds $(69.5 \%)$ were Christian, followed by Muslim (27.3\%). The highest percentage of respondents had a secondary level of education $(69.7 \%)$ followed by higher 
secondary and above (16.9\%). The majority of them were housewife (76.9\%) and the rest were engaged in services or other jobs.
The median income was MYR 1000.0, and the average family size was 5.9.

Table 1. Socio-demographic characteristics of the respondents $(n=1236)$

\begin{tabular}{|c|c|c|c|c|}
\hline \multirow[t]{2}{*}{ Characteristics } & \multirow[t]{2}{*}{ Frequency } & \multirow[t]{2}{*}{$\%$} & \multicolumn{2}{|c|}{$95 \% C I$} \\
\hline & & & $\begin{array}{l}\text { Lower } \\
\text { Bound }\end{array}$ & $\begin{array}{c}\text { Upper } \\
\text { Bound }\end{array}$ \\
\hline \multicolumn{5}{|l|}{ Age in years } \\
\hline$<20$ & 77 & 6.2 & 4.9 & 7.5 \\
\hline $20-29$ & 667 & 54.0 & 51.1 & 56.9 \\
\hline $30-39$ & 438 & 35.4 & 32.6 & 38.1 \\
\hline $40-49$ & 54 & 4.4 & 3.3 & 5.5 \\
\hline Mean (SD) years & \multicolumn{2}{|c|}{$28.3(6.1)$} & 28.0 & 28.7 \\
\hline \multicolumn{5}{|l|}{ Ethnicity } \\
\hline Malay & 219 & 17.7 & 15.5 & 19.8 \\
\hline Iban & 494 & 40.0 & 37.1 & 42.6 \\
\hline Bidayuh & 375 & 30.3 & 27.9 & 32.8 \\
\hline${ }^{\mathrm{a}}$ Others & 148 & 12.0 & 10.2 & 13.8 \\
\hline \multicolumn{5}{|l|}{ Religion } \\
\hline Christian & 859 & 69.5 & 67.0 & 72.0 \\
\hline Muslim & 337 & 27.3 & 24.8 & 29.8 \\
\hline Non-Muslim & 40 & 3.2 & 2.3 & 4.3 \\
\hline \multicolumn{5}{|l|}{ Level of education } \\
\hline No formal education & 25 & 2.0 & 1.3 & 2.8 \\
\hline Primary & 141 & 11.4 & 9.6 & 13.2 \\
\hline Secondary & 861 & 69.7 & 67.1 & 72.1 \\
\hline Higher secondary and above & 209 & 16.9 & 14.9 & 19.0 \\
\hline \multicolumn{5}{|l|}{ Occupation } \\
\hline Housewife & 951 & 76.9 & 74.4 & 79.2 \\
\hline Government & 132 & 10.7 & 8.9 & 12.5 \\
\hline Private & 109 & 8.8 & 7.3 & 10.4 \\
\hline Self employed & 44 & 3.6 & 2.6 & 4.6 \\
\hline \multicolumn{5}{|l|}{ Household income (MYR) } \\
\hline$<1000$ & 586 & 47.4 & 44.7 & 50.5 \\
\hline $1000-1999$ & 356 & 28.8 & 26.4 & 31.4 \\
\hline$\geq 2000$ & 294 & 23.8 & 21.4 & 26.1 \\
\hline Median & \multicolumn{2}{|c|}{1000.00} & 950.00 & 1000.00 \\
\hline \multicolumn{5}{|l|}{ Family size } \\
\hline $2-3$ & 170 & 13.8 & 11.8 & 15.7 \\
\hline $4-5$ & 467 & 37.8 & 34.9 & 40.6 \\
\hline $6-7$ & 334 & 27.0 & 24.4 & 29.6 \\
\hline$\geq 8$ & 265 & 21.4 & 19.2 & 23.7 \\
\hline Mean (SD) & \multicolumn{2}{|c|}{$5.9(2.5)$} & 5.8 & 6.0 \\
\hline
\end{tabular}

CI= Confidence interval

${ }^{a}$ Others includes minority group in Sarawak 


\section{Delivery Care}

Nearly one hundred per cent of the women delivered their children in the government hospital or clinic, and very few of them delivered their children in private clinics. More than half of the birth attendants were nurses (53.6\%) followed by doctors $(29.9 \%)$. The majority had normal vaginal delivery $(83.9 \%)$ and $16.1 \%$ was instrumental delivery, such as cesarean section or forceps delivery. Similar to the birth attendant, more than two-fifths
(44.7\%) of the post-delivery attendants were nurses followed by doctors $(34.7 \%)$. However, one-fifth $(20.6 \%)$ of them were attended by both doctors and nurses. The median out of pocket expenses was MYR 170.0 ranging from 0 Ringgit to 6000 Ringgit. Due to the skewed distribution of out of pocket expenses, it was categorized into four quartiles. The lowest quartile had expenses less than MYR 91.5 (25\%) and the first quartile to the third quartile (MYR 91.5 to 337.49$)$ was (50\%) and above the third quartile was $25 \%$.

Table 2. Percentage distribution of the respondents by selected delivery care $(n=1236)$

\begin{tabular}{|c|c|c|c|c|}
\hline \multirow[t]{2}{*}{ Characteristics } & \multirow{2}{*}{ Frequency } & \multirow[t]{2}{*}{$\%$} & \multicolumn{2}{|c|}{$95 \% \mathrm{CI}$} \\
\hline & & & $\begin{array}{l}\text { Lower } \\
\text { Bound }\end{array}$ & $\begin{array}{l}\text { Upper } \\
\text { Bound }\end{array}$ \\
\hline \multicolumn{5}{|l|}{ Birth attendant } \\
\hline Doctor & 370 & 29.9 & 27.4 & 32.5 \\
\hline Nurse & 663 & 53.6 & 50.8 & 56.4 \\
\hline Both & 203 & 16.4 & 14.3 & 18.5 \\
\hline \multicolumn{5}{|l|}{ Mode of delivery } \\
\hline Normal & 1037 & 83.9 & 81.8 & 86.0 \\
\hline Instrumental & 199 & 16.1 & 14.0 & 18.2 \\
\hline \multicolumn{5}{|c|}{ Post-delivery attendant } \\
\hline Doctor & 429 & 34.7 & 32.2 & 37.4 \\
\hline Nurse & 552 & 44.7 & 41.7 & 47.2 \\
\hline Both & 255 & 20.6 & 18.5 & 23.1 \\
\hline \multicolumn{5}{|c|}{ Out of pocket Expenses (RM) } \\
\hline$<91.50$ & 309 & 25.0 & 22.9 & 27.3 \\
\hline $91.50-337.49$ & 618 & 50.0 & 47.2 & 52.7 \\
\hline$\geq 337.50$ & 309 & 25.0 & 22.6 & 27.3 \\
\hline Median (RM) & \multicolumn{2}{|c|}{170.0} & 150.0 & 200.0 \\
\hline
\end{tabular}

$\mathrm{CI}=$ Confidence interval

\section{Level of satisfaction in delivery care}

The level of satisfaction in delivery care services was determined by seven domains of satisfaction. Each domain has several Likert's scale questions which scored ' 1 ' as highly disagree, ' 2 ' as disagree, ' 3 ' as neither agree or disagree, ' 4 ' as agree and ' 5 ' as highly agree. A high score indicating a higher level of satisfaction. A composite domain means, and the standard deviation was calculated based on the item of questions. Table 3 illustrates the domain-wise and overall mean level of satisfaction on delivery care services. The highest mean score was in the interpersonal communication (mean $=3.98$; $\mathrm{SD}=0.6$ ) followed closely by financial satisfaction (mean=3.96; $\mathrm{SD}=0.6$ ); the technical quality aspect (mean $=3.94$; $\mathrm{SD}=0.6$ ); supportive services (mean $=3.82$; $\mathrm{SD}=0.4$ ) and clinic staff (mean $=3.74$; $\mathrm{SD}=0.6)$. The lower mean scores were inaccessibility of healthcare (mean $=3.53$; $\mathrm{SD}=0.6)$ and duration with staff aspect (mean=3.41; $\mathrm{SD}=0.7$ ). The overall satisfaction mean score for delivery care services was 3.77 with a standard deviation of 0.4. The minimal score was 1.52 and a 
maximal score of 5.0. The median score was 3.74 .

Table 3. Mean score of level of satisfaction by different delivery care aspects $(n=1236)$

\begin{tabular}{lcccccc}
\hline \multicolumn{1}{c}{ Domains } & No. of Items & Mean & SD & Median & Minimum & Maximum \\
\hline Technical quality & 4 & 3.94 & 0.59 & 4.00 & 1.50 & 5.00 \\
Financial aspect & 3 & 3.96 & 0.64 & 4.00 & 1.33 & 5.00 \\
supportive services & 6 & 3.82 & 0.44 & 3.83 & 1.50 & 5.00 \\
Clinic/hospital staff & 5 & 3.74 & 0.56 & 3.80 & 1.00 & 5.00 \\
Accessibility & 4 & 3.53 & 0.55 & 3.50 & 1.25 & 5.00 \\
Interpersonal aspect & 2 & 3.98 & 0.62 & 4.00 & 1.00 & 5.00 \\
Time with Doctor & 2 & 3.41 & 0.67 & 3.50 & 1.00 & 5.00 \\
Overall satisfaction & 26 & 3.77 & 0.41 & 3.73 & 1.52 & 5.00 \\
\hline SD= Standard deviation
\end{tabular}

$\mathrm{SD}=$ Standard deviation

\section{Factors affecting Level of Satisfaction on Delivery Care: Multinomial Logistic Regression Analysis}

A multinomial logistic regression analysis was undertaken to examine the factors affecting the level of satisfaction with delivery care among the participants (Pallant, 2016; Tabachnick \& Fidell, 2013). The satisfaction score on delivery care was categorized into three based on quartiles. Below the first quartile as poorly satisfied, the interquartile range from first to the third quartile as average and above the third quartile was considered as good satisfaction. The analysis revealed that $23.4 \%$ had poorly satisfied and $49.8 \%$ average satisfied and $26.9 \%$ had good satisfaction with delivery care. Initially, a bivariate analysis with chi-square test was done. Four variables such as ethnicity, religion, birth attendant and out of pocket expenses appeared to be statistically significant $(\mathrm{p}<0.05)$. These variables were entered into the multinomial regression model. In the final full model, three variables appeared to be statistically significant $(\mathrm{p}<0.05)$, such as ethnicity, birth attendant and out of pocket expenses. The full model containing the predictors were statistically significant $\left[\chi^{2}(\mathrm{df})=63.02(1800\right.$; $\mathrm{p}<0.001]$ indicating that the model was able to distinguish between respondents who were satisfied or poorly satisfied with delivery care, which indicated that the full model statistically significantly predicts the dependent variable better than the interceptonly model. This model contains the four independent variables explained between 5\% (Cox and Snell R square) and 5.7\% (Nagelkerke $\mathrm{R}$ squared) of the variance in the level of satisfaction. It is also able to classify $50 \%$ of the cases. The goodness of fit indices was not statistically significant $\left[\chi^{2}(d f)=161.967(146) ; \quad p>0.05\right] \quad$ which indicate no violation of assumption.

Multinomial logistic regression analysis revealed that Bidayuh were $28.6 \%$ less likely to have better satisfaction with delivery care than the other ethnic groups. However, the respondent was 1.806 times likely to have average satisfied and 1.972 times more likely to have good satisfaction on delivery care if a doctor attended the delivery. Similarly, the respondents were 2.291 times highly satisfied if the out of pocket expenses were less than MYR 91.50 (US \$21.73) compared to 2.104 times in the average satisfaction group. However, religion had no impact on satisfaction on delivery care $(\mathrm{p}>0.05)$ 
Table 4. Factors affecting the level of satisfaction on delivery care: Multinomial logistic regression analysis

\begin{tabular}{|c|c|c|c|c|c|c|c|c|}
\hline \multirow{3}{*}{ Characteristics } & \multicolumn{4}{|c|}{ Average satisfaction } & \multicolumn{4}{|c|}{ Good Satisfaction } \\
\hline & \multirow[b]{2}{*}{$\boldsymbol{\beta}$} & \multirow[b]{2}{*}{ Adj OR } & \multicolumn{2}{|c|}{$95 \% \mathrm{CI}$} & \multirow[b]{2}{*}{$\beta$} & \multirow[b]{2}{*}{ Adj OR } & \multicolumn{2}{|c|}{$95 \% \mathrm{C}$} \\
\hline & & & $\begin{array}{l}\text { Lower } \\
\text { Bound }\end{array}$ & $\begin{array}{l}\text { Upper } \\
\text { Bound }\end{array}$ & & & $\begin{array}{l}\text { Lower } \\
\text { Bound }\end{array}$ & $\begin{array}{l}\text { Upper } \\
\text { Bound }\end{array}$ \\
\hline \multicolumn{9}{|l|}{ Ethnicity } \\
\hline Malays & 0.339 & 1.404 & 0.720 & 2.735 & 0.243 & 1.276 & 0.624 & 2.609 \\
\hline Iban & -0.181 & 0.835 & 0.450 & 1.547 & -0.108 & 0.897 & 0.450 & 1.791 \\
\hline Bidayuh & -0.557 & 0.573 & 0.307 & 1.069 & $-0.714^{*}$ & 0.490 & 0.241 & 0.995 \\
\hline${ }^{\mathrm{a} O t h e r s}(\mathrm{RC})$ & & 1 & & & & 1 & & \\
\hline \multicolumn{9}{|l|}{ Religion } \\
\hline Christianity & -0.504 & 0.604 & 0.252 & 1.450 & 0.805 & 2.236 & 0.604 & 8.275 \\
\hline Muslim & -0.716 & 0.489 & 0.180 & 1.330 & 0.867 & 2.380 & 0.585 & 9.681 \\
\hline $\begin{array}{l}\text { bNon-Muslim } \\
\text { (RC) }\end{array}$ & & 1 & & & & 1 & & \\
\hline \multicolumn{9}{|l|}{ Birth attendant } \\
\hline Doctor & $0.591 *$ & 1.806 & 1.131 & 2.882 & $0.679 *$ & 1.972 & 1.166 & 3.336 \\
\hline Nurse & 0.135 & 1.145 & 0.764 & 1.715 & 0.068 & 1.071 & 0.671 & 1.708 \\
\hline Both (RC) & 1 & & & & & 1 & & \\
\hline \multicolumn{9}{|c|}{ Out of pocket expenses (RM) } \\
\hline$<91.50$ & $0.744 * *$ & 2.104 & 1.373 & 3.225 & $0.829 * *$ & 2.291 & 1.407 & 3.731 \\
\hline $91.50-337.49$ & $0.497 * *$ & 1.644 & 1.156 & 2.339 & $0.560 * *$ & 1.750 & 1.162 & 2.635 \\
\hline$\geq 337.50(\mathrm{RC})$ & & 1 & & & & 1 & & \\
\hline Constant & 0.858 & & & & -1.135 & & & \\
\hline
\end{tabular}

Dependent variable $=$ Level of satisfaction (poor satisfaction as reference)

Model Chi square $(d f)=63.024(18) ; p<0.001$

Goodness of fit chi square $(d f)=161.967(146) ; p>0.05$

${ }^{*} p<0.05 ; * * p<0.01 ; * * * p<0.001$

${ }^{a}$ Others includes minority group in Sarawak

${ }^{b}$ non-Muslim includes paganism, atheist, Hindu and Buddhist

\section{DISCUSSION}

A very high percentage of women delivered in health facilities utilizing delivery care services. The majority are in government hospital (95\%) and a few numbers in non-governmental facilities $(5 \%)$ as seen in this study. The safe motherhood program initiation and $100 \%$ safe delivery policy of the Malaysian Ministry of Health has been carried out extensively as Malaysia continues the effort to achieve the Millennium Development Goal 2015 and extending to the Sustainable Developmental Goals after the year 2015 (Yadav, 2012). Other countries have shown the private facility use was more than $70 \%$ (Changole et al., 2010). More than threequarters of the respondents had normal deliveries, similar to other findings such as in Sri Lanka (Amentie et al., 2016), Malawi (Changole et al., 2010) and Canada (Bélanger-Lévesque et al., 2014). More than half of the women's delivery was attended by nurses only (Changole et al., 2010), less attended by doctors only and a smaller portion attended by both doctors and nurses. In Sarawak, normal uncomplicated deliveries can be attended by trained, skilled nurses in all health facilities including hospital settings and smaller $\mathrm{MCH}$ clinics manned by 
community nurses with midwifery background. The medical doctors attend complicated deliveries which are a smaller number as compared to the high number of normal deliveries in this study.

The women in this study were found to be satisfied with the delivery care services received above an average mean score. High levels of satisfaction regarding delivery care were found in other countries, such as in Nigeria (Dhar et al., 2009), Scotland (Sandall et al., 2016), Bangladesh (Kebede et al., 2016) and South Africa (Lumadi \& Buch, 2011). In this study, women were highly satisfied in terms of technical quality, financial aspect, supportive services and interpersonal aspect (Amentie et al., 2016). They were, however, found to be least satisfied with accessibility and lowest with a duration of consultation or treatment. The low satisfaction was the 'human factor' aspects which were accessibility to medical doctors and obstetrician could be due to the shortage of staff while the normal cases were usually attended to by mostly nurses instead of specialists.

Three determinants of good satisfaction were found in this study, namely ethnicity, birth attendant and out of pocket expenses spent during the last delivery. Ethnicity as determinants of satisfaction level of delivery care services was also found in separate studies in Sri Lanka (Amentie et al., 2016). This is also seen in Maori, whereby women were culturally bound and were less likely to be satisfied with the delivery care provision (Ratima \& Crengle, 2013). The minimum out of pocket expenses during last delivery was one of the determinants of satisfaction (Srivastava, Avan, Rajbangshi, \& Bhattacharyya, 2015), whereby some communities were dissatisfied with the service given due to high delivery costs, as seen in Bangladesh (Varma et al., 2010). Other studies found that even though the delivery costs were high for lower socioeconomic women, nonetheless, they were still satisfied as they could afford it (Dhar et al., 2009). It is also noted that the antenatal care services provided in the government setting are free. However, delivery care services would be charged a minimal amount of fee in a government hospital setting. The women then would need to prepare a higher amount of budget for delivery care services as compared to the antenatal and postnatal care in Sarawak.

This study also found that caregivers affect good satisfaction (above average) on delivery care services, in particular, the level of skill or professionalism (nurses or doctors). This is consistent with another study done in Sri Lanka (Amentie et al., 2016), where women were found to be more satisfied when attended by medical doctors compared to nurses in a hospital setting. However, continuity of care by nurses seem to be preferred in a health facility delivery setting (Sandall et al., 2016) manned by midwives. Some women were more satisfied with nurses alone as birth attendant (Sandall et al., 2016); while there were women who were satisfied with both doctors and nurses attending their delivery (Changole et al., 2010; Khanam, Quazi Syed, \& Wagh, 2012). Women attended by doctors alone during the delivery process are differentiated from those attended by nurses and midwives as only complicated and abnormal pregnancies would be attended by doctors who require close monitoring and constant review. Christian and Muslim women were found to be highly satisfied as compared to others (paganism, atheist, Hindu and Buddhist). The ethnicity of women was also found to affect good satisfaction. The major ethnic groups were more satisfied as compared to Chinese and other minority groups. Notably, about 98 per cent of women had safe delivery by skilled birth attendants during their last delivery. This finding is encouraging as Sarawak strives to achieve $100 \%$ of safe delivery at present.

This study identified several limitations, such as the cross-sectional design and the dependence on recall 
memory of the respondents. In this study, mothers having the youngest child of three years and below, without making any comparison within this period, might represent an important recall bias. Another limitation is the area of study, where the respondents were mostly recruited from suburban and rural communities. This allows the findings to represent the community in these areas of Sarawak. It is recommended for future studies to include a qualitative method for deeper understanding, including longitudinal studies to confirm the temporal effect of the satisfaction and to cover all areas such as urban, suburban and rural communities for better representation of the whole state, and as a comparative study of the findings.

\section{CONCLUSION}

Overall, women were satisfied with the delivery care services provided in the hospital and $\mathrm{MCH}$ clinics. The factors associated with the level of satisfaction were ethnicity, expenses spent during the last delivery and birth attendant. The different level of satisfaction amongst different skilled professional birth attendants (such as nurses and doctors) suggests that there is a need for further assessment of satisfaction with the services provided from the different level of health care professionals for future planning to improve delivery care.

\section{REFERENCES}

Amano, A., Gebeyehu, A., \& Birhanu, Z. (2012). Institutional delivery service utilisation in Munisa Woreda, South East Ethiopia: A community-based cross-sectional study. BMC Pregnancy and Childbirth, 12, 105. https://doi.org/10.1186/1471-239312-105

Amentie, M., Muluemebetabera, \& abdulahi, M. (2016). The utilisation of institutional delivery care services and influencing factors among women of childbearing age in Assosa district, Benishangul Gumuz regional state, West Ethiopia. Global Journal of Medical Research, 16(3), 35-44.

Bélanger-Lévesque, M.-N., Pasquier, M., Roy-Matton, N., Blouin, S., \& Pasquier, J.-C. (2014). Maternal and paternal satisfaction in the delivery room: A cross-sectional comparative study. BMJ Open, 4(2), e004013.

https://doi.org/10.1136/bmjopen2013-004013

Changole, J., Bandawe, C., Makanani, B., Nkanaunena, K., Taulo, F., Malunga, E., \& Kafulafula, G. (2010). Patients' satisfaction with reproductive health services at Gogo Chatinkha Maternity Unit, Queen Elizabeth Central Hospital, Blantyre, Malawi. Malawi Medical Journal: The Journal of Medical Association of Malawi, 22(1), 5-9.

Darega, B., Dida, N., Tafese, F., \& Ololo, S. (2016). Institutional delivery and postnatal care services utilisations in Abuna Gindeberet District, West Shewa, Oromiya Region, Central Ethiopia: A Community-based cross-sectional study. BMC Pregnancy and Childbirth, 16(149), 1-7.

https://doi.org/10.1186/s12884016-0940-X

Das, S., Alcock, G., Azad, K., Kuddus, A., Manandhar, D. S., Shrestha, B. P., ... Osrin, D. (2016). Institutional delivery in public and private sectors in South Asia: A comparative analysis of prospective data from four demographic surveillance sites. BMC Pregnancy and Childbirth, 16, 273. https://doi.org/10.1186/s12884016-1069-7

Dhar, R. S. G., Nagpal, J., Sinha, S., Bhargava, V. L., Sachdeva, A., \& Bhartia, A. (2009). Direct cost of 
maternity-care services in South Delhi: A community survey. Journal of Health, Population, and Nutrition, 27(3), 368-378.

Dzomeku, M. V. (2011). Maternal satisfaction with care during labour: A case study of the MampongAshanti district hospital maternity unit in Ghana. International Journal of Nursing and Midwifery, 3(3), 3034.

Garson, G. D. (2015). Missing values analysis and data imputation (second).

IBM SPSS. (2013). IBM SPSS Statistics for Windows (Version 22). Armonk, New York, USA: IBM SPSS.

Kaur, J. (2011). Maternal health in malaysia: A review. WebmedCentral Public Health, 2(12), 1-26.

Kebede, A., Hassen, K., \& Nigussie Teklehaymanot, A. (2016). Factors associated with institutional delivery service utilization in Ethiopia. International Journal of Women's Health, 8, 463-475. https://doi.org/10.2147/IJWH.S109 498

Kennare, R. M., Keirse, M. J. N. C., Tucker, G. R., \& Chan, A. C. (2010). Planned home and hospital births in South Australia, 1991-2006: Differences in outcomes. The Medical Journal of Australia, 192(2), 76-80.

Khanam, N., Quazi Syed, Z., \& Wagh, V. (2012). Patient satisfaction on maternal and child health services. Indian Medical Gazette, 1(1), 4751.

Kyei, N. N. A., Campbell, O. M. R., \& Gabrysch, S. (2012). The influence of distance and level of service provision on antenatal care use in rural Zambia. PLOS ONE, 7(10), e46475.

https://doi.org/10.1371/journal.pon e. 0046475
Lumadi, T. G., \& Buch, E. (2011). Patients' satisfaction with midwifery services in a regional hospital and its referring clinics in the Limpopo Province of South Africa. Africa Journal of Nursing and Midwifery, 13(2), 14-28.

Pallant, J. (2016). Spss survival manual: A step by step guide to data analysis using spss (6th edition).

Pitaloka, S. D., \& Rizal, A. M. (2006). Patients' satisfaction in antenatal clinic hospital Universiti Kebangsaan Malaysia. Jurnal Kesihatan Masyarakat, 12(1), 9-18.

Rahman, M. M. (1997). Socio-demographic determinants of infant mortality and morbidity and its correlation with maternal health in slum dwellers of Dhaka city. Dhaka University, Dhaka.

Ratima, M., \& Crengle, S. (2013). Antenatal, labour, and delivery care for Māori: Experiences, location within a lifecourse approach, and knowledge gaps. Pimatisiwin: A Journal of Aboriginal and Indigenous Community Health, 10(3), 353-366.

Sandall, J., Soltani, H., Gates, S., Shennan, A., \& Devane, D. (2016). Midwifeled continuity models versus other models of care for childbearing women. The Cochrane Database of Systematic Reviews, 4, CD004667. https://doi.org/10.1002/14651858.C D004667.pub5

Sarawak State Health Department. (2003). Klinik kesihatan. Management manual (4th ed.). Kuching, Sarawak: Sarawak State Health Department.

Srivastava, A., Avan, B. I., Rajbangshi, P., \& Bhattacharyya, S. (2015). Determinants of women's satisfaction with maternal health care: A review of literature from developing countries. BMC Pregnancy and Childbirth, 15, 97. 
https://doi.org/10.1186/s12884-

015-0525-0

Tabachnick, B. G., \& Fidell, L. S. (2013).

Using multivariate statistics (6th ed).

Varma, D. S., Khan, M., \& Hazra, A. (2010). Increasing institutional delivery and access to emergency obstetric care services in rural Uttar Pradesh. The Journal of Family Welfare, 56, 23-30.

World Health Organization, UNICEF, UNFPA and The World Bank. (2012). Trends in maternal mortality: 1990 to 2010, WHO, UNICEF, UNFPA and The World Bank estimates.

Yadav, H. (2012). A review of maternal mortality in Malaysia. IeJSME, 6(Suppl 1), S142-S151.

Yohannes, B., Tarekegn, M., \& Paulos, W. (2013). Mothers' utilization of antenatal care and their satisfaction with delivery services in selected public health facilities of Wolaita zone, Southern Ethiopia. International Journal of Scientific \& Technology Research, 2(2), 7485. 